\title{
O MECANISMO DE TRANSMISSÃO DA POLÍTICA MONETÁRIA NO BRASIL: UMA ANÁLISE EM VAR POR SETOR INDUSTRIAL
}

\author{
Eduardo Cardeal Tomazzia \\ Roberto Meurer ${ }^{\dagger}$
}

\begin{abstract}
Resumo
Este artigo analisa o impacto de choques monetários nas principais variáveis macroeconômicas e no produto de setores industriais, no Brasil, entre 1999 e 2008. É utilizada a metodologia de modelos VAR, pela abordagem de Toda \& Yamamoto (1995), e funções de impulso-resposta. Verificou-se robustez dos modelos e efetividade da política monetária no período. Os setores industriais respondem negativamente à política monetária exógena, mas com diferença no nível do efeito. Os setores de bens de consumo duráveis apresentam a maior resposta, os de bens de demanda industrial uma reação intermediária, e o de bens de consumo não duráveis a menor resposta.
\end{abstract}

Palavras-chave: mecanismo de transmissão monetária, efeitos setoriais, Brasil, metas de inflação

JEL classification: E23, E59, E32

\begin{abstract}
This paper aims to analyze the impact of monetary shocks on main macroeconomic and industrial disaggregated production variables, between 1999 and 2008, in Brazil. We used the VAR methodology, developed by Toda \& Yamamoto (1995), and formulation of impulse-response functions. Results show robustness of the models, and effectiveness o monetary policy over the period. Industrial sectors respond negatively to exogenous monetary policy, but show difference on the effect level. Durable goods sectors show the highest response to monetary policy, industrial demand goods sectors have an intermediary reaction, and nondurable goods sector shows the less significant response.
\end{abstract}

Palavras-chave: monetary transmission mechanism, sectoral effects, Brazil, inflation targeting

JEL classification: E23, E59, E32

\footnotetext{
* Universidade Federal de Santa Catarina - Centro Sócio-Econômico - Campus Universitário Trindade Florianópolis - Santa Catarina

† Universidade Federal de Santa Catarina - Centro Sócio-Econômico - Campus Universitário Trindade Florianópolis - Santa Catarina
} 


\section{Introdução}

Desde os estudos seminais de Bernanke \& Blinder (1992) e Sims (1992), uma extensa literatura vem sendo desenvolvida para a aplicação de modelos VAR na mensuração dos efeitos de choques de política monetária em variáveis macroeconômicas, uma metodologia cuja grande inovação é não requerer a formulação de modelos estruturais mais completos.

No Brasil, a temática foi abordada em estudos como os de Minella (2003), Arquete \& Jayme-Jr. (2003), Fernandes \& Toro (2005) e Céspedes et al. (2008), que analisam a resposta das principais variáveis macroeconômicas, como produto, inflação, taxa de câmbio e agregados monetários à política monetária.

Um tema de destaque atual é a análise dos efeitos setoriais da política monetária. Este aspecto tem profundas implicações para uma gestão macroeconômica que considera efeitos diversos sobre os setores da economia e a divisão regional da produção. Portanto, uma inovação de política com pouca repercussão no agregado pode conduzir a grandes restrições em alguns setores, e ainda apresentar dinâmica temporal de transmissão heterogênea. Adicionalmente, o conhecimento desta dinâmica setorial pode levar a um conhecimento mais profundo dos mecanismos de transmissão de política monetária.

Entre os estudos iniciais nesta área, destacam-se os de Gertler \& Gilchrist (1993) e Bernanke \& Gertler (1995), que analisam a economia americana e encontram evidências da grande relevância do canal de transmissão de crédito. Estudos mais recentes, como os de Ganley \& Salmon (1997), Favero \& Giavazzi (1999), Arnold \& Vrugt (2002), Dedola \& Lippi (2005), Ibrahim (2005) e Alam \& Waheed (2006), desenvolvem a temática de efeitos setoriais da política monetária para um grande número de países.

Estendendo este campo de pesquisa para o Brasil, este artigo tem como objetivo principal mensurar a resposta de setores industriais específicos à política monetária exógena, entre eles: bens de consumo duráveis, não duráveis, construção civil, bens de capital, bens intermediários e veículos automotivos, de modo a contribuir para o alargamento de evidências empíricas dos efeitos setoriais heterogêneos, tanto em nível de impacto como em defasagem de efeito. Além disso, o estudo tem como objetivo secundário a mensuração do impacto de choques monetários nas principais variáveis macroeconômicas e a inter-relação da definição da variável de política monetária no Brasil sob o regime de metas inflacionárias.

A metodologia utilizada é a aplicação de modelos VAR, com o tratamento de não-estacionariedade das variáveis pelo método descrito por Toda \& Yamamoto (1995). Parte-se de um modelo geral da economia brasileira, com o instrumento de política monetária e as variáveis que compõem a função de reação da autoridade monetária, de modo a separar o componente exógeno da política monetária. Em seguida são formulados modelos VAR incorporando as séries de produção setorial para mensurar a sua resposta à política monetária exógena. A análise é feita a partir das funções impulso-resposta, com a utilização da taxa básica de juros da economia brasileira - a Selic - como o instrumento de política monetária no modelo, seguindo a definição de estudos como os de Bernanke \& Blinder (1992), Bernanke \& Gertler (1995), Bernanke \& Mihov (1998), Christiano et al. (1999) e Dedola \& Lippi (2005).

Na próxima seção são revisados os mecanismos de transmissão da política monetária e os possíveis efeitos na diferença setorial do impacto de uma inovação monetária, dos estudos de mensuração de política monetária no Brasil. 
A seção 3 discute o ambiente macroeconômico e a política monetária no período recente. Na sequência é apresentada a metodologia da pesquisa, a seção 5 traz os resultados e sua discussão, e a seção 6 as considerações finais.

\section{Política monetária e seus mecanismos de transmissão}

O mecanismo de transmissão monetária é definido por Taylor (1995) como "o processo através do que as decisões de política monetária são transmitidas para o produto real e a inflação". ${ }^{1}$ Deste modo, as decisões de política monetária podem ser modeladas como mudanças na taxa de juros de curto prazo definida pelo Banco Central. Estas mudanças afetam o produto real por meio de variáveis como oferta de crédito, riqueza, renda, taxa de câmbio real e custo de capital.

O canal da taxa de juros se dá pela estrutura a termo da taxa de juros, com a propagação da taxa de juros de curto prazo determinada pela política monetária - para a de longo prazo, influenciando a taxa de juros real, o custo de capital, alterando o custo de oportunidade dos agentes e, consequentemente, o investimento e o consumo. Apesar de ser uma das primeiras relações identificadas entre a definição de medidas monetárias e a atividade real da economia, que remonta à teoria keynesiana, Bernanke \& Gertler (1995) acusam a baixa evidência empírica deste mecanismo, principalmente no tocante a seu efeito no custo de capital.

No Brasil, estudos como os de Lima \& Issler (2003) e Marçal \& Pereira (2007) aceitam apenas parcialmente a estrutura a termo da taxa de juros. As suposições levantadas sobre a baixa evidência empírica da suscetibilidade das taxas de juros de longo prazo à política monetária passam pela ineficiência informacional dos mercados a termo, como decorrência da própria política monetária e mesmo pela presença de mudança estrutural relevante na economia brasileira recente.

Quanto às diferenças setoriais, Arnold \& Vrugt (2002) afirmam que as empresas diferem em sua resposta à política monetária pelo lado da demanda, dependendo da função de consumo dos bens considerados. Assim, esperase uma resposta maior e mais rápida sobre indústrias produtoras de bens de capital (efeito sobre outras empresas) e de consumo durável (efeito sobre os consumidores), diante do aumento do custo de capital, e uma reação mais baixa de bens de consumo não duráveis, por se tratarem de bens de primeira necessidade e baixo valor unitário, que possuem baixa elasticidade em relação à renda e não dependerem de concessão de crédito para a sua compra.

O mecanismo de câmbio ocorre, segundo Mishkin (1996), ao afetar a competitividade e as exportações líquidas, via variação da taxa de câmbio real, ao menos no curto prazo. Deste modo, a exposição desigual dos diversos setores industriais à competição internacional é o que daria origem à diferença setorial.

Um efeito relevante para o caso brasileiro é o impacto da taxa de câmbio na inflação - efeito pass-through - que ocorre pela incorporação dos custos associados a insumos importados e bens comercializáveis (tradables) nos preços. Desta forma, setores com maior participação de bens importados em seus insumos estariam mais expostos à restrição monetária. O impacto da taxa de câmbio nos preços da economia tem grandes efeitos na política monetária, que

\footnotetext{
${ }^{1}$ Tradução dos autores.
} 
precisa antecipar o efeito da taxa de câmbio sobre a inflação e o produto, principalmente sob o regime de metas inflacionárias. Este efeito foi identificado por Goldfajn \& Werlang (2000) para vários países, incluindo o Brasil. Correa \& Minella (2005) investigam a não-lineariedade no repasse cambial aos preços, e identificam um maior coeficiente de repasse quando a economia está em expansão, quando a taxa de câmbio apresenta baixa volatilidade e quando a depreciação é maior. Schwartzman (2006) estima a curva de Phillips na economia brasileira recente, e verifica que não existe um repasse cambial direto aos bens não comercializáveis. Identifica, por outro lado, repasse cambial direto aos bens comercializáveis, e indireto aos demais bens. Tejada \& Silva (2008) mensuram os coeficientes de pass-through para vários tradables no Brasil, e identificam uma média de $14 \%$ para a transmissão da taxa de câmbio nos preços destes produtos, um coeficiente considerado baixo.

Um terceiro canal do mecanismo pode ser chamado de canal do preço dos ativos, e pode ser dividido pelo seu efeito por dois meios. O primeiro ocorre pela decisão de investimento das empresas, que se dá pela avaliação da relação entre o valor de mercado de uma empresa e seu custo de reposição de capital, definição do $q$ de Tobin. Quanto maior esta relação, maior o incentivo das empresas a investirem, por considerarem que a sua capacidade de gerar fluxos de caixa captada pela percepção do mercado de seu valor é maior em relação ao seu custo de reposição.

$\mathrm{O} q$ de Tobin pode ser afetado de várias formas pela política monetária. A principal se dá pelo valor das ações das empresas. Uma retração monetária reduz o numerário disponível na economia, além de tornar os títulos públicos mais atrativos, reduzindo assim a demanda das ações e, consequentemente, o seu preço. Outra forma de afetar o $q$ de Tobin é pela alteração do custo de reposição, um canal que interage com o canal do câmbio. O efeito de uma política contracionista na taxa de câmbio ocasiona um aumento imediato do preço dos insumos importados e eleva indiretamente o preço dos demais insumos internos, dado o efeito pass-through, o que aumenta o custo de reposição.

Um segundo meio do canal do preço dos ativos afeta as decisões de consumo das famílias pela variação da sua riqueza. Conforme a teoria do ciclo de vida de Modigliani, o gasto com consumo é suavizado ao longo da vida, e uma redução da riqueza presente e futura das famílias é compensada por uma redução no seu consumo presente (Mishkin 1996).

Lima \& Jorge-Neto (2004) encontram evidências do impacto da política monetária sobre o preço das ações mais líquidas, a partir de um estudo de eventos com empresas brasileiras. Este canal pode se tornar relevante para o consumo das famílias se a participação dos consumidores no mercado acionário for relevante, o que não parece ser o caso do Brasil. Por outro lado, este resultado confirma o impacto da política monetária no $q$ de Tobin, afetando o investimento das empresas.

Uma importante característica do canal do preço dos ativos é a relação com a estrutura da dívida pública, em que quanto maior o prazo médio da dívida e menor a participação de títulos indexados à Selic, maior o poder do mecanismo (Lopes 1997).

Neste sentido, Barbosa (2006) identifica o efeito contágio da dívida pública na política monetária brasileira. Para o autor a taxa de juros interbancária brasileira é alta porque os títulos atrelados à Selic, com duration nulo, que compõe boa parte dos títulos ofertados pelo Tesouro, são substitutos perfeitos das reservas bancárias. Desta forma, não existe a possibilidade de dissociação 
da política monetária de efeitos na dívida pública, nem mesmo de operações de dívida sem a contrapartida no mercado de reservas bancárias.

Complementarmente, Pires \& Andrade (2008) analisam o papel da composição da dívida pública na transmissão da política monetária. Os autores afirmam que em um contexto de restrição monetária, a parcela da dívida atrelada à Selic gera um efeito renda positivo, estimula a demanda agregada, e reduz o efeito da política monetária. Portanto, a menor participação de títulos indexados à Selic gera maior estabilidade nos modelos testados, tornando a política monetária mais efetiva.

De modo geral, pode-se afirmar que uma política monetária restritiva teria o resultado de reduzir a riqueza das famílias e o valor de mercado das empresas, reduzindo, também por este meio, o investimento e consumo (Mishkin 1996). Para os objetivos deste estudo, pode-se afirmar que diferenças setoriais na riqueza e no $q$ de Tobin levariam a diferentes efeitos da política monetária.

O canal de transmissão do crédito, proveniente do prêmio pelo financiamento externo à firma, como descrito em Bernanke \& Gertler (1995), vai ao encontro da emergente teoria da assimetria de informação nos mercados bancário e financeiro (Freixas \& Rochet 1999). Este se divide em dois canais, de empréstimo bancário e do balanço, que ocorrem devido ao deslocamento da oferta de crédito e da mudança da posição financeira dos devedores (redução do valor das garantias e de receitas), respectivamente. Diferenças em efeitos setoriais podem surgir pela capacidade de autofinanciamento ou acesso a outras fontes de financiamento, como captação desintermediada, que requer maior escala para compensar os custos fixos.

Quanto à relevância deste canal na economia brasileira, pode-se citar Graminho \& Bonomo (2002), que a partir de dados bancários desagregados, encontram uma relação positiva entre a contração monetária e o lucro dos bancos brasileiros, o que resulta em aumento de sua liquidez e capacidade de empréstimo quando ocorre uma elevação da taxa Selic. Este resultado indica a inexistência de um canal de empréstimos bancários no Brasil.

Takeda, Rocha \& Nakane (2005) também verificam a não efetividade da taxa de juros para restringir a liquidez dos bancos. Por outro lado, verificam que o aumento dos depósitos compulsórios tem efeitos na oferta de crédito dos bancos.

Em contrapartida, Carneiro et al. (2006), a partir de dados agregados, identificam a existência, no Brasil, de um canal de transmissão da taxa de juros sobre a demanda por crédito, em direção ao investimento das empresas. A contração da demanda por crédito ocorre devido à redução da oferta de garantias pelas empresas. Apesar de não conclusivos, mesmo os estudos que refutam a existência de alguns dos mecanismos de crédito afirmam que o canal do crédito é relevante e que mais pesquisas são necessárias para avaliar melhor sua influência nos efeitos de política monetária.

Quanto à mensuração da transmissão da política monetária na economia brasileira, existem alguns estudos relevantes, que devem ser mencionados. Minella (2003) analisa a transmissão da política monetária para o produto, inflação, taxa de juros e agregados monetários com a metodologia de modelos VAR, em três períodos distintos - 1975/1985, 1985/1994 e 1994/2000 e constata que a política monetária se tornou efetiva no combate à inflação no terceiro período, mesmo que com baixa intensidade. Além disso, conclui que possui efeito significativo no produto e em agregados monetários, para todos os períodos, além de identificar a existência de um price puzzle, pois 
ocorre uma elevação da inflação imediatamente após a contração monetária, no segundo período.

Em estudo semelhante, Arquete \& Jayme-Jr. (2003) utilizam a metodologia VAR para examinar a política monetária brasileira de 1994 a1994 a 2002. Entre suas principais conclusões identificam o efeito da Selic sobre o hiato do produto entre o segundo e o sexto mês após o choque, e que a política monetária tem dificuldade em controlar a inflação, dada a sua baixa sensibilidade à taxa Selic, além do importante papel das variáveis externas - taxa de câmbio e reservas internacionais - na Selic e no hiato do produto. Além disso, as relações das variáveis componentes do modelo de modo geral cessam entre $12 \mathrm{e}$ 20 meses após os choques.

Fernandes \& Toro (2005) estimam o mecanismo de transmissão monetária por modelo de VAR cointegrado - um Vector Error Correction Model (VECM) para o período de 1996 a1996 a 2001. O mecanismo de transmissão monetária é definido pelos autores como a relação causal entre a intervenção monetária, por meio de instrumentos como a taxa de juros de curto prazo e oferta de moeda, e as metas finais - taxas de juros de longo prazo, inflação e produto. Neste sentido, a política monetária e sua transmissão são identificadas na estimação das relações de longo prazo e na dinâmica de ajuste de curto prazo das variáveis macroeconômicas em um modelo VECM, além da estimação de funções de impulso- resposta, sendo o choque exógeno de política monetária decorrente da taxa de juros de curto prazo. Os autores identificam três relações de longo prazo entre o estoque real de moeda, renda real, inflação e taxas de juros de curto e longo prazo, que correspondem (i) à relação negativa entre o hiato do produto e a taxa de juros real (curva IS); (ii) à determinação do nível de reservas em função da velocidade da moeda; e (iii) à regra de reação monetária do Banco Central. Os autores também verificam o impacto da política monetária nos componentes do modelo, e a resposta do nível de atividade é inicialmente negativa, sendo anulado por uma reação positiva até o sexto mês do efeito. A inflação e a oferta real de moeda, por outro lado, respondem consistentemente de forma negativa, e as taxas de juros de forma positiva. A defasagem de efeito máximo, para as variáveis analisadas, gira em torno de três meses, e o efeito cessa em, no máximo, oito meses.

A partir da metodologia de VAR estrutural, Céspedes, Lima \& Issler (2003) examinam os efeitos da política monetária sobre a inflação, produção industrial, taxa de câmbio nominal, taxas de juros de curto e longo prazo, agregado monetário e reservas internacionais para dois períodos da economia brasileira - 1996/1998 e 1999/2004. Os achados do estudo indicam que no primeiro período a inflação responde negativamente à Selic, mesmo que com pouca significância, devido à grande dificuldade para mensurar os efeitos de política monetária em uma amostra tão pequena. Para o segundo período, identificam que a elevação da Selic gera os efeitos esperados de uma política monetária contracionista: a taxa de câmbio é apreciada, e o produto e a inflação diminuem, além de constatarem, em modelos com maior defasagem, a existência do price puzzle. 


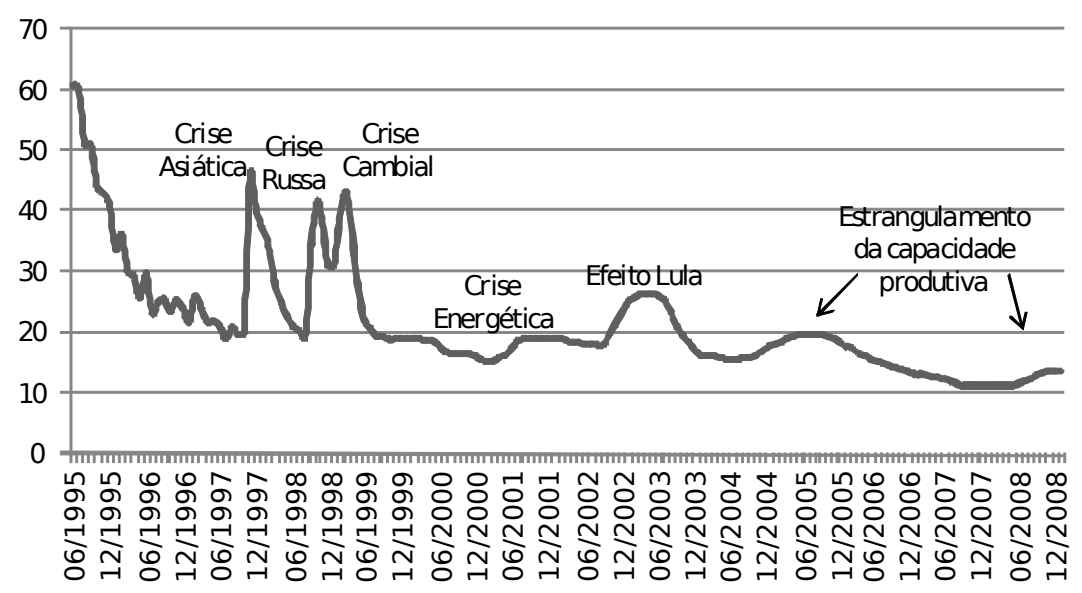

Figura 1: Taxa Selic em \% a.a. - 06/1995 a 12/2008

\section{A política monetária brasileira a partir da estabilização monetária}

Com a adoção do Plano Real e a estabilização monetária, Lopes (1997) constata que os mecanismos de transmissão da política monetária voltaram a se fortalecer, o que ocorreu gradualmente. Um aspecto importante que, a priori, divide o período pós-estabilização é o regime de câmbio, semifixo no primeiro e flutuante no segundo, o que constitui uma mudança, em 1999, do instrumento de política, da taxa de câmbio para taxas de juros. Se a taxa de juros, até janeiro de 1999, era em boa parte uma variável macroeconômica de absorção de choques externos, a partir de então passou a ser o instrumento principal da política monetária, sob o regime de metas de inflação, com diferente impacto na economia real. Silva-Filho et al. (2006) identificam um período de grande turbulência das variáveis macroeconômicas e evidências empíricas de queda momentânea da eficiência da política monetária nos cinco primeiros meses de 1999.

Outras transformações relevantes ao longo do período podem ser apontadas, como a redução do crowding out (Caballero \& Krishnamurthy 2004), pela introdução de metas fiscais para tentar controlar os desequilíbrios nas contas públicas (Giambiagi 2002, 2006), e também o aumento das operações de crédito e grande queda do spread bancário (Oreiro et al. 2006).

Quanto à variável principal do presente estudo, a taxa básica de juros da economia brasileira, cabe uma análise mais acurada, feita a partir da Figura 1.

Ao longo do período podem ser observados sete choques de elevação da taxa de juros, seguidos por movimentos de redução. Como esperado em termos teóricos, durante o período de câmbio semifixo as oscilações na taxa de juros são mais abruptas, pela necessidade de interferências no mercado de câmbio e a finitude das reservas internacionais. Após a adoção da taxa de câmbio flutuante há autonomia da política monetária, que passa a ter maior efeito sobre o produto. No período de câmbio semifixo os eventos mais diretamente causadores das elevações da taxa de juros foram a crise asiática no 
final de 1997 e a crise russa em setembro de 1998. Na transição para o câmbio flutuante há outra elevação da taxa de juros, no início de 1999. No período de câmbio flutuante há quatro ciclos de elevação da taxa de juros. O primeiro se dá ao longo de 2001, com o objetivo de conter a demanda agregada ante limitações da capacidade produtiva, exacerbadas com a crise energética. A partir de setembro de 2002 a 2002 a taxa de juros é elevada na tentativa de contraporse aos efeitos da depreciação da moeda brasileira com a fuga de recursos no período pré-eleitoral, o que vem sendo chamado de 'Efeito Lula'. Em setembro de 2004 é iniciado mais um ciclo de elevação dos juros, com o objetivo de controlar a expansão da demanda agregada, novamente em um contexto de estrangulamento da capacidade produtiva da indústria, o que ocorre novamente entre abril e setembro de 2008. No período de câmbio flutuante estas elevações da taxa são revertidas quando a inflação e suas expectativas estão compatíveis com as metas, o que é possível por meio de menor expansão da demanda e crescimento da capacidade produtiva.

\section{Metodologia}

É generalizadamente aceito que a política monetária tem efeitos sobre o produto real, pelo menos no curto prazo. Em termos empíricos, entretanto, a avaliação destes efeitos não é tão simples. Um bom exemplo dessa discussão é Romer \& Romer (1989), em que à utilização de VAR é sugerida a alternativa de "abordagem narrativa", que resgata a metodologia de Friedman \& Schwartz (1963). Porém, esta abordagem também é sujeita a arbitrariedades, como mostra a interessante discussão que segue o artigo de Romer \& Romer (1989). Estes utilizam como critério para isolar o efeito do choque monetário sobre o produto e o desemprego a preocupação da autoridade monetária com a inflação corrente, o que significa considerar que a inflação não influencia o produto, mas, por outro lado, a política monetária influencia tanto a inflação quanto o desemprego e o produto.

O principal problema da mensuração dos impactos de política monetária é a dificuldade de isolar os seus efeitos reais, dado que outras variáveis também influenciam o produto, assim como a identificação do seu componente exógeno, que não está condicionado pelas condições macroeconômicas ou, em outros termos, que não é captado pela função de reação do Banco Central.

Segundo Bernanke \& Mihov (1998), existem duas formas de se mensurar a política monetária exógena. A primeira trata da já mencionada abordagem narrativa, que analisa as intenções da autoridade monetária por meio de seus relatórios, declarações e ações, com um resultado mais qualitativo que quantitativo, se restringindo a definir se a política é contracionista ou expansionista. Esta abordagem é válida para uma pesquisa qualitativa, mas possui o problema de ser subjetiva e fornecer pouca informação, principalmente quanto aos diferentes níveis da contração e expansão da política monetária.

A segunda abordagem, esta muito mais utilizada na literatura, emprega as informações consideradas pelo Banco Central, para separar os componentes endógeno e exógeno da política monetária. Para tanto, utilizam-se técnicas de estimação em Vetores Auto-Regressivosem Vetores Auto-Regressivos (VAR), que não impõem uma estrutura rígida de causalidade entre as variáveis, e consegue traçar as relações entre todas elas. Neste contexto, a principal variável utilizada como proxy de política monetária é a taxa básica de juros da 
economia, definida pela autoridade monetária. Desta forma, este trabalho foca a abordagem em modelos VAR. Aem modelos VAR. A amostra temporal escolhida inicia-se no mês de adoção da política de metas de inflação, junho de 1999, e vai até dezembro de 2008. Ao adotar um período com uma política monetária constante em termos qualitativos - metas inflacionárias - procurase evitar os problemas decorrentes da Crítica de Lucas (1976), que poderiam trazer mais problemas ao se adotar uma amostra maior.

Quanto às propriedades de estacionariedade das séries utilizadas, optouse por não realizar análise de cointegração no sistema estimado. Esta opção está baseada nos achados de Sims et al. (1990), que mostram que para modelos auto-regressivos, a transformação das variáveis para a sua primeira diferença e os testes de cointegração e do mecanismo de correção se torna desnecessária, e que os resultados de testes em nível são consistentes assintoticamente. Ademais, esta suposição vem sendo adotada por estudos de várias economias, como os de Bernanke \& Gertler (1995) (EUA), Dedola \& Lippi (2005) (países desenvolvidos) e Céspedes et al. (2008) (Brasil).

Adotou-se neste estudo o tratamento de estacionariedade do VAR estimado, baseado em Toda \& Yamamoto (1995), que demonstram que as propriedades estatísticas permanecem robustas, para um VAR em nível com variáveis com ordem de integração e cointegração desconhecidas se defasagens adicionais, iguais ao número de integração máxima das variáveis, forem adicionadas ao número ótimo de defasagens do modelo. A questão posta pelos autores é que, primeiramente, os testes de raízes unitárias são muito imprecisos contra a alternativa da hipótese de as variáveis serem estacionárias com tendência. Além disso, é muito difícil saber a priori se as variáveis são estacionárias com tendência, integradas ou cointegradas, e de que ordem. Uma última razão da escolha do uso das variáveis em nível é a perda de informação ao se trabalhar em primeira diferença.

Diante do exposto o modelo a ser testado é um VAR reduzido, como segue:

$$
X_{t}=c+\sum_{i=1}^{p} B_{i} X_{t-i}+\Gamma Z_{t}+\varepsilon_{t},
$$

sendo que $X_{t}$ é o vetor das variáveis endógenas; $Z_{t}$ é o vetor das variáveis exógenas; $B_{i}$ e $\Gamma_{i}$ são as matrizes dos coeficientes; $c$ é um vetor de constantes; $p$ é o número de defasagens; e $\varepsilon_{t}$ é o vetor de erro do sistema, sendo que $\varepsilon_{t} \sim N(0, \Sigma)$ e $E\left(\varepsilon_{t}, \varepsilon_{s}\right) \neq 0$, sendo $t \neq s$.

Deste modo, os resíduos são contemporaneamente correlacionados, uma vez que a matriz $\sum$ não é diagonal. Portanto, os resíduos do VAR são resultados de uma combinação linear de choques exógenos não correlacionados contemporaneamente, e não é possível a identificação do choque exógeno de cada variável endógena do sistema. Em termos de avaliação de política monetária, esta é uma restrição que leva à necessidade de um método para tornar os resíduos não correlacionados contemporaneamente, que torne a matriz $\Sigma$ diagonal. Adota-se neste trabalho a decomposição de Choleski. As suposições adotadas nesta opção tornam a ordenação das variáveis no sistema a estrutura de causalidade contemporânea, sendo que a primeira variável afeta todas as outras contemporaneamente, sem ser afetada, a segunda é afetada apenas pela primeira e afeta todas as outras, e assim sucessivamente, tornando-o um 
sistema recursivo. ${ }^{2}$

A escolha do número ótimo de defasagens é feita por testes de seleção de defasagem em VAR, utilizando o Critério de Informação de Schwarz, e adicionado o número máximo de integração das variáveis do sistema, estimado pelos testes de raiz unitária Phillip-Perron (PP) e Augmented Dickey-Fuller (ADF).

A mensuração dos efeitos da política monetária nos setores industriais foi realizada em duas etapas, seguindo a abordagem encontrada em Dedola \& Lippi (2005), que apresenta a vantagem de testar um modelo geral, seguido dos modelos específicos, que contém as variáveis setoriais, e testar a robustez separadamente.

O Modelo Geral Principal (MGP) inclui como variáveis endógenas a variável de política monetária - a taxa básica de juros - e as informações a que o Banco Central reage, entre elas proxies do produto, nível de preços, taxa de câmbio, e agregados monetário e de crédito. Este modelo principal segue a especificação de trabalhos realizados para a economia americana, como Bernanke \& Gertler (1995), Christiano et al. (1999), com a inclusão da variável de câmbio, que a torna semelhante a estudos da economia brasileira como Minella (2003) e Arquete \& Jayme-Jr. (2003), e de estudos de outras economias abertas, como Dedola \& Lippi (2005), e também da variável de crédito, de modo a separar os efeitos de choques no crédito.

A ordenação adotada para o método de decomposição de Choleski foi: produto, nível de preços, taxa básica de juros, agregado monetário, nível de crédito e taxa de câmbio. ${ }^{3}$ Deste modo, as suposições sobre a estrutura adotada são semelhantes às verificadas em Minella (2003), Christiano et al. (1999) e Dedola \& Lippi (2005): o nível de produção não responde contemporaneamente às demais variáveis, uma vez que as decisões de produção e seu efeito sobre a produção final ocorrem apenas com alguma defasagem, que é maior que a periodicidade adotada (mensal); o nível de preços pode ser afetado contemporaneamente apenas pela produção, uma vez que o mercado de bens é dinâmico, ocorrendo ajustes nos preços, decorrentes de alterações na sua oferta e demanda com uma periodicidade menor que um mês; a taxa básica de juros responde contemporaneamente ao produto e ao nível de preços, considerando que a autoridade monetária tem informações razoáveis sobre o comportamento destes, que incorporam na sua decisão de política monetária; os agregados monetário e de crédito respondem às variáveis anteriores, por se tratarem de variáveis dinâmicas, que respondem com alta freqüência; e a taxa de câmbio é a variável mais dinâmica do sistema, e responde a qualquer choque às outras variáveis contemporaneamente. A taxa de câmbio é uma das variáveis mais voláteis no período analisado, e responde aos choques externos, ajustando as variações do prêmio de risco dos investidores externos, considerando a paridade descoberta de juros e o regime de câmbio flutuante.

De modo a testar a robustez do modelo, além de verificar relações importantes não identificadas no modelo principal, mais parcimonioso, foram estimados dois modelos alternativos:

\footnotetext{
${ }^{2}$ A descrição do sistema recursivo pode ser visto em Christiano, Eichenbaum e Evans (1999).

${ }^{3}$ A ordenação adotada identifica três blocos de variáveis: as mais exógenas contemporaneamente representam o mercado de bens, incluindo produção e preços, a intermediária representa a variável de política monetária, que responde contemporaneamente ao mercado de bens, e as mais endógenas representam o mercado financeiro (agregado monetário, crédito e câmbio), que reagem às anteriores, mas não as afetam contemporaneamente.
} 
Modelo Geral de Economia Aberta (MGEA) Este modelo explicita relações importantes de uma economia aberta e pequena, conforme discutido por Cushman \& Zha (1997). São inseridas as variáveis importação e exportação como variáveis endógenas e ordenadas antes do produto, pois se supõe que os contratos de exportação e importação não são afetados contemporaneamente pela produção geral. Inclui-se também como variável endógena um índice de risco-país, que representa o prêmio de risco cobrado pelo investimento externo de curto e médio prazo no Brasil, e reflete informações internas e o impacto das crises financeiras globais que afetaram várias das variáveis endógenas. Esta variável foi ordenada em último lugar, uma vez que é definida em base diária, e decorre de negociação de títulos da dívida soberana brasileira no mercado secundário. Como variáveis exógenas são acrescentadas o nível externo de preços (commodities) e a taxa básica de juros americana (Federal Funds Rate), que não são afetadas pelas variáveis internas da economia brasileira, mas que as afetam.

A inflação externa de commodities, uma medida de choques externos de oferta, é uma informação importante para melhorar a estimação da função de reação do Banco Central, e consequentemente do choque exógeno de política monetária na inflação interna, com o propósito de se evitar o price puzzle. A taxa básica de juros americana indica o custo de oportunidade do capital internacional (taxa de juros livre de risco) e é relevante por considerar a relação da taxa de juros interna e da taxa de câmbio sob a paridade descoberta de juros.

Modelo Geral com Expectativas (MGE) São consideradas informações de expectativas da taxa de juros e de inflação. Deste modo é possível captar o papel da formação das expectativas na transmissão da política monetária. A estrutura a termo da taxa de juros também é importante para a estimação do efeito não esperado da política monetária. A variável de expectativas de inflação é inserida antes do nível de preços na ordenação, uma vez que a série utilizada representa a expectativa formada no início do mês corrente em relação à inflação a ser registrada ao fim do mês seguinte e, portanto, deve afetar a formação de preços ao longo do mês corrente. A expectativa da taxa de juros foi ordenada logo após a taxa básica de juros, de modo que é afetada contemporaneamente por esta. Um último diferencial deste modelo é o período de estimação, que se inicia em março de 2000, uma vez que a disponibilidade dos dados de expectativa de inflação, coletados pelo Banco Central do Brasil, se inicia neste mês.

Para testar o efeito da política monetária exógena nos setores, foram formulados seis modelos VAR adicionais com a variável de produção industrial de cada setor. Os índices de produção em quantum foram utilizados como proxies do produto real dos respectivos setores. O índice de produção de insumos de construção civil foi utilizado como proxy do produto real da construção civil. Estas variáveis foram ordenadas logo após o produto nos modelos VAR, supondo-se que, como uma variável de produção industrial, não pode ser afetada contemporaneamente por nenhuma outra no sistema, a não ser a própria produção industrial geral, ou pelas variáveis ordenadas antes delas, no caso do MGEA. A robustez dos modelos foi testada por meio das mesmas 
variações dos modelos VAR propostos no modelo geral. A descrição das séries utilizadas é realizada na Tabela 1 . As séries de produção industrial foram utilizadas em sua forma dessazonalizada, disponibilizada pelo IBGE. Para as demais variáveis, foi utilizado o teste combinado para a presença de sazonalidade identificável na rotina de dessazonalização X12 do US Census Bureau, e dessazonalizadas, pelo mesmo método, as variáveis que apresentaram tal característica.

Por fim, o foco deste estudo não está na análise dos coeficientes, uma vez que o modelo VAR é, por natureza, super-parametrizado. O interesse está nas funções de impulso-resposta. Para tal fim, parte-se da transformação do VAR para um VMA (Vector Moving Average), do qual se pode mensurar a resposta das variáveis endógenas a choques exógenos (Enders 2004). Como já descrito, foi adotado o método de decomposição de Choleski, que utiliza o fator da matriz de covariância dos resíduos invertida para ortogonalizar os impulsos.

\section{Resultados e discussão}

\subsection{Modelo Geral}

Inicialmente foram realizados os testes de raiz unitária Phillip-Perron (PP) e Augmented Dickey-Fuller (ADF) e quase todas as variáveis apresentaram uma raiz unitária, sendo estacionárias na sua primeira diferença, ou seja, são $I(1)$. As variáveis SELIC e EI apresentaram resultados divergentes entre os testes, sendo a primeira estacionária em nível no $\mathrm{ADF}$, mas não no $\mathrm{PP}$, e a segunda o inverso. As variáveis SWAP, EX, IMP e PIBCND se mostraram estacionárias em nível para ambos os testes quando se inclui o intercepto, mas não sem o mesmo. O fato de haver variáveis com ordens de integração diferentes e ambigüidade no resultado de outras confirma a opção pela metodologia de VAR de Toda e Yamamoto (1995). Além disso, identifica-se uma defasagem adicional para os modelos (maior número de integração verificado).

O primeiro modelo estimado foi o MGP. O teste de defasagem ótima indicou duas defasagens, o que resultou na definição de três defasagens. A estimação do modelo com quatro e cinco defasagens não distorceu os resultados qualitativos, alterando principalmente o intervalo de confiança, devido à perda de graus de liberdade ao se aumentar o número de parâmetros estimados. As funções de impulso-resposta são evidenciadas na Figura 2.

A resposta da produção industrial confirma a neutralidade de longo prazo e efetividade de curto prazo da política monetária sobre o produto. O nível da produção industrial é reduzido em até $-0,5 \%$ com oito meses de defasagem, e retorna ao seu nível inicial em até dois anos após o choque. O rápido efeito da política monetária sobre as principais variáveis macroeconômicas no Brasil já vem sendo verificado em estudos como os de Minella (2003) e Céspedes et al. (2008), e contrasta com o resultado de países desenvolvidos, notadamente os EUA, cujo efeito máximo ocorre entre um e dois anos após o choque, conforme verificado por Bernanke \& Gertler (1995), Bernanke \& Mihov (1998) e Dedola \& Lippi (2005). A rapidez do efeito máximo no Brasil é explicada por Minella (2003) pela predominância do crédito de curto prazo na economia brasileira. Desta forma a taxa de juros incidente sobre os contratos de dívida tem uma parcela maior da de curto prazo, e o espalhamento da taxa de juros básica sobre esta estrutura é mais rápida. 
Tabela 1: Nome, descrição e fonte das variáveis utilizadas

\begin{tabular}{|c|c|c|c|}
\hline Variável & Sigla & Descrição da proxy & Fonte \\
\hline \multicolumn{4}{|c|}{ Modelo Geral } \\
\hline $\begin{array}{l}\text { Instrumento de } \\
\text { política } \\
\text { monetária }\end{array}$ & SELIC & Taxa de juros - Over / Selic - (\% a.a.) & $\begin{array}{c}\text { BCB } \\
\text { Boletim/MF }\end{array}$ \\
\hline Produto & PIG & $\begin{array}{l}\text { Produção industrial - indústria geral - } \\
\text { quantum - índice dessaz. (média } 2002= \\
\text { 100) - em logaritmos naturais }\end{array}$ & IBGE/PIM-PF \\
\hline Taxa de Câmbio & CAMBIO & $\begin{array}{l}\text { Taxa de câmbio - R\$ / US\$ - comercial - } \\
\text { venda - fim período - em logaritmos } \\
\text { naturais }\end{array}$ & $\begin{array}{c}\text { BCB } \\
\text { Boletim/BP }\end{array}$ \\
\hline $\begin{array}{l}\text { Nível de Preços } \\
\text { Interno }\end{array}$ & IGPM & $\begin{array}{l}\text { IGPM - geral - índice (ago. } 1994=100) \\
\text { - em logaritmos naturais }\end{array}$ & $\begin{array}{l}\text { FGV/Conj. } \\
\text { Econ. }\end{array}$ \\
\hline $\begin{array}{l}\text { Agregado } \\
\text { Monetário }\end{array}$ & M1 & $\begin{array}{l}\text { M1 - Base monetária e meios de } \\
\text { pagamento - fim período - R } \$ \text { (milhões) } \\
\text { (deflator: IPCA) - dessazonalizado pelo } \\
\text { método X12 (US Census Bureau) - em } \\
\text { logaritmos naturais }\end{array}$ & $\begin{array}{c}\text { BCB } \\
\text { Boletim/Moeda }\end{array}$ \\
\hline $\begin{array}{l}\text { Agregado de } \\
\text { Crédito }\end{array}$ & OCSP & $\begin{array}{l}\text { Operações de crédito ao setor privado } \\
\text { (deflator: IPCA) - R\$(milhões) - em } \\
\text { logaritmos naturais }\end{array}$ & $\begin{array}{c}\text { BCB } \\
\text { Boletim/Moeda }\end{array}$ \\
\hline $\begin{array}{l}\text { Expectativa de } \\
\text { Inflação }\end{array}$ & EI & $\begin{array}{l}\text { Expectativa de inflação do final do mês } \\
\text { seguinte no início do mês corrente (\% } \\
\text { a.m.) }\end{array}$ & $\begin{array}{l}\text { Elaborado com } \\
\text { base nos dados } \\
\text { do BCB/FOCUS }\end{array}$ \\
\hline $\begin{array}{l}\text { Taxa de Juros de } \\
\text { Longo Prazo }\end{array}$ & SWAP & $\begin{array}{l}\text { Taxa referencial - swaps - DI pré-fixada - } \\
360 \text { dias - fim de período - (\% a.a.) }\end{array}$ & $\mathrm{BM} \& \mathrm{~F}$ \\
\hline Importações & IMP & $\begin{array}{l}\text { Importações - US } \$ \text { milhões - } \\
\text { transformado para R } \$ \text { por série de taxa } \\
\text { de câmbio R } \$ \text { /US } \$ \text { comercial, venda, } \\
\text { fim de período (deflator: IPCA) - em } \\
\text { logaritmos naturais - dessazonalizado } \\
\text { pelo método X12 (US Census Bureau) }\end{array}$ & $\begin{array}{c}\text { BCB } \\
\text { Boletim/BP }\end{array}$ \\
\hline Exportações & EX & $\begin{array}{l}\text { Exportações - US } \$ \text { milhões - } \\
\text { transformado para R } \$ \text { por série de taxa } \\
\text { de câmbio R } \$ \text { /US } \$ \text { comercial, venda, } \\
\text { fim de período (deflator: IPCA) - em } \\
\text { logaritmos naturais - dessazonalizado } \\
\text { pelo método X12 (US Census Bureau) }\end{array}$ & $\begin{array}{c}\text { BCB } \\
\text { Boletim/BP }\end{array}$ \\
\hline Risco País & EMBI & $\begin{array}{l}\text { Índice de Risco-País EMBI+ Brasil - em } \\
\text { logaritmos naturais }\end{array}$ & JP Morgan \\
\hline $\begin{array}{l}\text { Nível de Preços } \\
\text { Externo }\end{array}$ & CPI & $\begin{array}{l}\text { Commodity Price Index (jan. } 2005=100 \text { ) } \\
\text { - em logaritmos naturais }\end{array}$ & FMI \\
\hline $\begin{array}{l}\text { Taxa básica de } \\
\text { Juros } \\
\text { Internacional }\end{array}$ & FFR & $\begin{array}{l}\text { Taxa dos fundos federais - Fed Funds } \\
\text { Rate (custo de reservas bancárias por } \\
\text { um dia), no mercado norte-americano } \\
\text { (a.a.\%) }\end{array}$ & IFS \\
\hline
\end{tabular}


Tabela 1: Nome, descrição e fonte das variáveis utilizadas (continuação).

\begin{tabular}{|c|c|c|c|}
\hline Variável & Sigla & Descrição da proxy & Fonte \\
\hline \multicolumn{4}{|c|}{ Modelos Específicos } \\
\hline $\begin{array}{l}\text { Produção } \\
\text { Industrial de } \\
\text { Bens de Capital }\end{array}$ & PIBC & $\begin{array}{l}\text { Produção industrial - bens de capital - } \\
\text { quantum - índice dessaz. (jan. } 2002= \\
\text { 100), em logaritmos naturais }\end{array}$ & IBGE/PIM-PF \\
\hline $\begin{array}{l}\text { Produção } \\
\text { Industrial de } \\
\text { Bens de } \\
\text { Consumo } \\
\text { Duráveis }\end{array}$ & PIBCD & $\begin{array}{l}\text { Produção industrial - bens de consumo } \\
\text { duráveis - quantum - índice dessaz. (jan. } \\
2002=100 \text { ), em logaritmos naturais }\end{array}$ & IBGE/PIM-PF \\
\hline $\begin{array}{l}\text { Produção } \\
\text { Industrial de } \\
\text { Bens de } \\
\text { Consumo Não } \\
\text { Duráveis }\end{array}$ & PIBCND & $\begin{array}{l}\text { Produção industrial - bens de consumo } \\
\text { não duráveis - quantum - índice dessaz. } \\
\text { (jan. } 2002=100 \text { ), em logaritmos } \\
\text { naturais }\end{array}$ & IBGE/PIM-PF \\
\hline $\begin{array}{l}\text { Produção } \\
\text { Industrial - } \\
\text { Construção } \\
\text { Civil }\end{array}$ & PICC & $\begin{array}{l}\text { Produção industrial - insumos - } \\
\text { construção civil - quantum - índice } \\
\text { dessaz. (jan. } 2002=100 \text { ), em logaritmos } \\
\text { naturais }\end{array}$ & IBGE/PIM-PF \\
\hline $\begin{array}{l}\text { Produção } \\
\text { Industrial de } \\
\text { Bens } \\
\text { Intermediários }\end{array}$ & PIBI & $\begin{array}{l}\text { Produção industrial - bens } \\
\text { intermediários - quantum - índice } \\
\text { dessaz. (jan. } 2002=100 \text { ), em logaritmos } \\
\text { naturais }\end{array}$ & IBGE/PIM-PF \\
\hline $\begin{array}{l}\text { Produção } \\
\text { Industrial de } \\
\text { Veículos } \\
\text { Automotores }\end{array}$ & PIVA & $\begin{array}{l}\text { Produção industrial - veículos } \\
\text { automotores - quantum - índice dessaz. } \\
\text { (jan. } 2002=100) \text {, em logaritmos } \\
\text { naturais }\end{array}$ & IBGE/PIM-PF \\
\hline
\end{tabular}

O choque de política monetária no nível de preços também se mostrou significativo, com redução de $0,8 \%$ ao fim dos 24 meses. O price puzzle se mostrou insignificante, visto que a relação inicial positiva se mostrou pequena $(0,07 \%)$ e de curta duração, o que é uma indicação, segundo Christiano et al. (1999)), de boa especificação do modelo.

O M1 se comporta de modo previsto pela teoria monetária, sendo que a demanda por moeda tende a reduzir a um aumento no custo de oportunidade ao se reter meios de pagamento líquidos, com um efeito máximo de quase $-2 \%$ em oito meses. O crédito ao setor privado apresenta uma queda permanente pouco menor que $1 \%$ e a taxa de câmbio, por outro lado, apresenta resposta muito pequena à inovação monetária neste modelo.

A resposta da SELIC às outras variáveis endógenas mostra as características da função de reação do Banco Central. As variáveis de maior influência na determinação da taxa de juros são ela mesma e a taxa de câmbio. A primeira relação, que ocorre com pequena defasagem, mostra uma característica autoregressiva importante e indica que a política monetária vem seguindo uma ação gradualista, como forma de evitar um overshooting. Desta forma, a SELIC atinge sua tendência de longo prazo em torno de um ano após o choque inicial de política monetária. A resposta à taxa de câmbio atinge seu ponto máximo (0,5 p.p.) em torno de dez meses, e o efeito cessa em pouco menos de dois anos. A defasagem deste efeito é semelhante ao do pass-trough cambial ao nível de preços, o que significa que o Banco Central apenas reage ao choque cambial na medida em que ele é transmitido para a inflação.

A resposta da SELIC a choques positivos de produção é inicialmente positiva, conforme o esperado. A reação ao choque no nível de preços é inicial- 


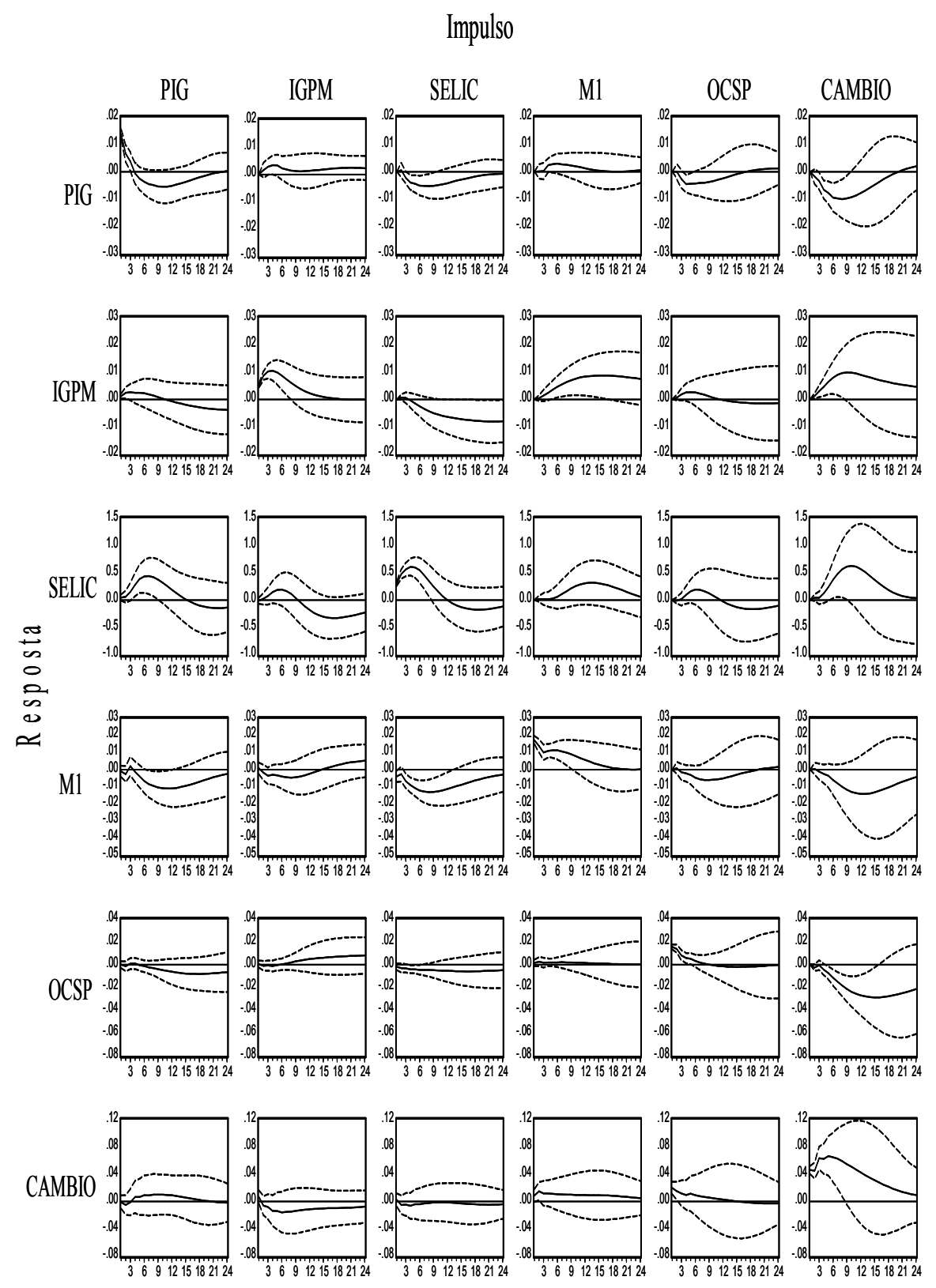

Obs.: Eixo Y: indica o nível de resposta, em percentual (à exceção da SELIC, em pontos percentuais) a um choque de um desvio-padrão da variável de impulso. Eixo X: defasagem do efeito, meses. Asem meses. As linhas tracejadas indicam o intervalo de confiança de 95\%.

Figura 2: Funções impulso - resposta do modelo geral principal 
mente positiva, sendo negativamente corrigido a partir de um ano. Os choques exógenos no nível de preços se mostram menos relevantes que as outras variáveis nas oscilações da SELIC, o que indica que o Banco Central esteja reagindo mais às outras fontes de choques inflacionários choques cambiais e de demanda. A resposta do nível de preços aos choques cambiais indica a existência de um efeito pass-through relevante, visto que o nível de preços chega a se elevar $1 \%$ diante de um choque cambial.

No Modelo Geral de Economia Aberta, o teste de Schwarz resultou em uma defasagem, e foram adotadas duas defasagens. Testes do modelo com três e quatro defasagens novamente mostraram funções de impulso-resposta robustas, com pequenas diferenças. Este modelo resultou em relações semelhantes às identificadas no MGP, como verificado na Figura 3. As relações verificadas entre a produção, o nível de preços e a política monetária foram semelhantes, sendo a que a produção apresenta uma resposta máxima ao choque monetário com menor defasagem, mas com mesma intensidade (-0,5\% em cinco meses), e a intensidade da resposta do IGPM mostrou-se um pouco menor $(-0,65 \%)$.

A resposta da SELIC aos choques das variáveis endógenas também se mostrou semelhante. Uma das diferenças foi o menor efeito da PIG, sendo que a inserção das exportações (com importante efeito positivo) pode ter melhorado a estimação do choque exógeno de produção. O efeito do IGPM se mostrou totalmente negativo, contrariando o efeito esperado, visto que o período analisado trata do regime de metas inflacionárias.

A inserção das variáveis externas também afetou as relações estimadas da taxa de câmbio, reduzindo principalmente o efeito desta nas demais. A inserção do EMBI parece ser o principal responsável, visto que as relações identificadas para ele são muito semelhantes às da taxa de câmbio. A resposta do CAMBIO à SELIC também é melhorada, e mostra uma valorização do Real frente ao Dólar americano de quase $1 \%$ após um choque monetário, com pequena defasagem e prolongamento do efeito.

As importações respondem inicialmente de forma positiva ao CAMBIO, e a partir de cinco meses de forma negativa. Esta é uma resposta esperada, uma vez que uma elevação da taxa de câmbio inicialmente eleva o valor total pago pelas importações porque os contratos são revistos com alguma defasagem, para em seguida reduzir o quantum de importação. A SELIC se mostrou relevante na redução tanto das importações como das exportações uma redução máxima de pouco menos de $2 \%$ em torno de meio ano e o efeito cessa em até dois anos. As exportações se mostraram mais relevantes ao afetarem a própria taxa SELIC, e afetam também o IGPM e a taxa de câmbio, e responde ao último de forma positiva e com pouca defasagem.

O modelo com expectativas foi modelado com duas defasagens. A estimação com três e quatro defasagens não mostrou diferença relevante das funções de impulso e resposta. As funções de impulso-resposta (Figura 4) mostram relações semelhantes às verificadas no MGP. O choque exógeno de política monetária reduz a produção industrial em no máximo $0,5 \%$, no sexto mês, e este efeito cessa em até dois anos. A inclusão da taxa de juros de longo prazo, mostrou uma resposta da produção industrial também às expectativas de juros, com efeito e defasagem de efeito máximo maiores $(-0,9 \%$ em nove meses).

Este resultado indica, entre outras coisas, que a política monetária, sob o regime de metas inflacionárias, tem obtido sucesso não apenas em afetar negativamente a produção por meio de um choque exógeno, mas também criou 


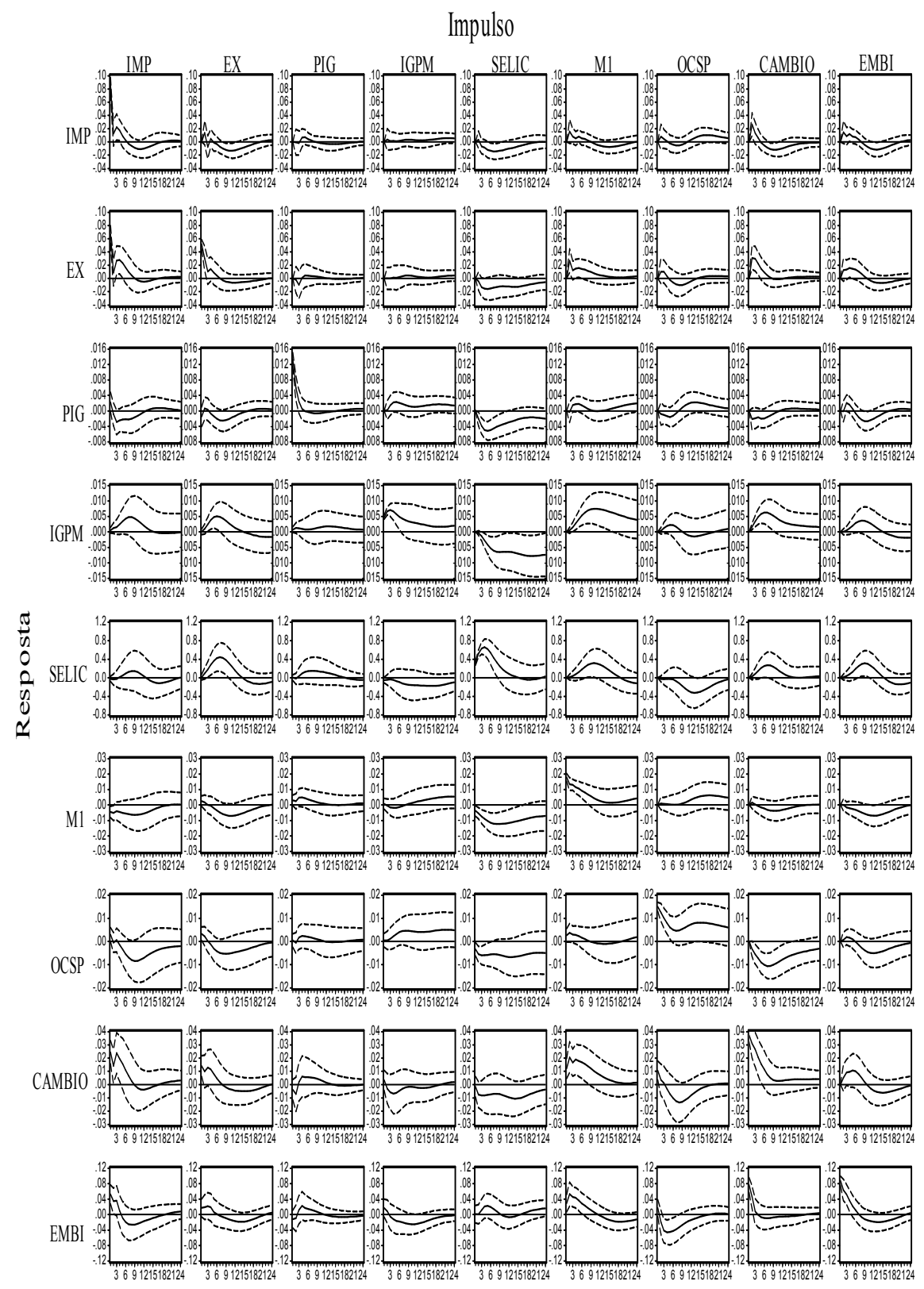

Obs.: Eixo Y: indica o nível de resposta, em percentual (à exceção da SELIC, em pontos percentuais) a um choque de um desvio-padrão da variável de impulso. Eixo X: defasagem do efeito,em meses. Asem meses. As linhas tracejadas indicam o intervalo de confiança de 95\%.

Figura 3: Funções de impulso - resposta do modelo geral de economia aberta 
uma reputação em que a sinalização de sua política futura, feita através de suas medidas e de seus pronunciamentos, tem efeitos reais sobre a economia. O impacto da taxa de juros de longo prazo na produção sugere que o canal de transmissão da taxa de juros é relevante na economia brasileira, pois há uma ligação entre a definição da taxa de juros de curto prazo, a geração de expectativas e a definição, pelos agentes econômicos, da taxa de juros futura que gera a estrutura a termo, e o impacto desta na produção. A resposta do SWAP a um choque exógeno na SELIC, e a resposta da última à primeira, são relevantes. O que não se pode afirmar é em que medida é o Banco Central sinaliza, gera expectativas e cumpre a sinalização. Uma possibilidade é que o Banco Central esteja, em parte, "seguindo o mercado", ou seja, atuando de forma a não ir contra as expectativas formadas. ${ }^{4}$

Neste modelo, não existe vestígio de price puzzle, ou seja, o IGPM não responde positivamente à SELIC em nenhuma defasagem, o que indica que a inserção das expectativas melhora o modelo. Entretanto, verificou-se um puzzle em relação à resposta das expectativas inflacionárias ao choque de política monetária, e também da resposta positiva tanto do EI quanto do IGPM à taxa de juros de longo prazo, o que merece investigação adicional. Guillèn (2008) verifica a aderência das expectativas inflacionárias brasileiras a modelos de rigidez informacional, com a constatação de um forte elemento auto-regressivo nas séries de expectativas de inflação. A demora ao ajuste das séries de expectativas consideradas neste trabalho pode explicar o efeito positivo inicial, que nada mais é que o espalhamento do efeito anterior à aplicação da contração monetária ou reversão das expectativas de taxa de juros, refletindo nos primeiros períodos após o choque.

\subsection{Modelos Setoriais}

Os modelos específicos com os Setores Industriais tiveram resultados interessantes, principalmente se analisados pelo lado da demanda dos bens. A Figura 5 mostra as funções de impulso-resposta da produção setorial a choques da SELIC, para os três modelos testados, e também o efeito do choque do SWAP na produção setorial, identificado no modelo MGE. De modo geral, a resposta dos setores aos choques de política monetária se mostrou similar de modelo para modelo, o que atesta a robustez dos resultados verificados.

A resposta da Indústria de Bens de Consumo Não Duráveis à inovação de política monetária é a menor verificada, com um efeito máximo um pouco menor que $-0,4 \%$, entre o oitavo e nono mês após o choque inicial. Este resultado confirma a expectativa de baixo efeito da política monetária sobre o consumo das famílias, o que suporta a teoria do ciclo de vida de Modigliani no Brasil sob o regime de metas de inflação. A taxa de juros de longo prazo apresentou efeito muito semelhante à SELIC na produção de Bens de Consumo Não Duráveis.

A Indústria de Bens de Consumo Duráveis apresenta a maior reação negativa ao choque monetário. O consumo desta categoria de bens, de alto preço unitário, é fortemente dependente de financiamento, sendo o seu custo um canal importante para a transmissão da política monetária. O efeito máximo

\footnotetext{
${ }^{4}$ Este efeito foi identificado teoricamente por modelos de equilíbrio geral em Ball (1995) e Chari, Christiano e Eichenbaum (1998), que defendem que o objetivo de evitar os custos sociais de desapontar as expectativas dos agentes privados pode até mesmo ser uma das fontes dos choques exógenos de política monetária.
} 
Impulso
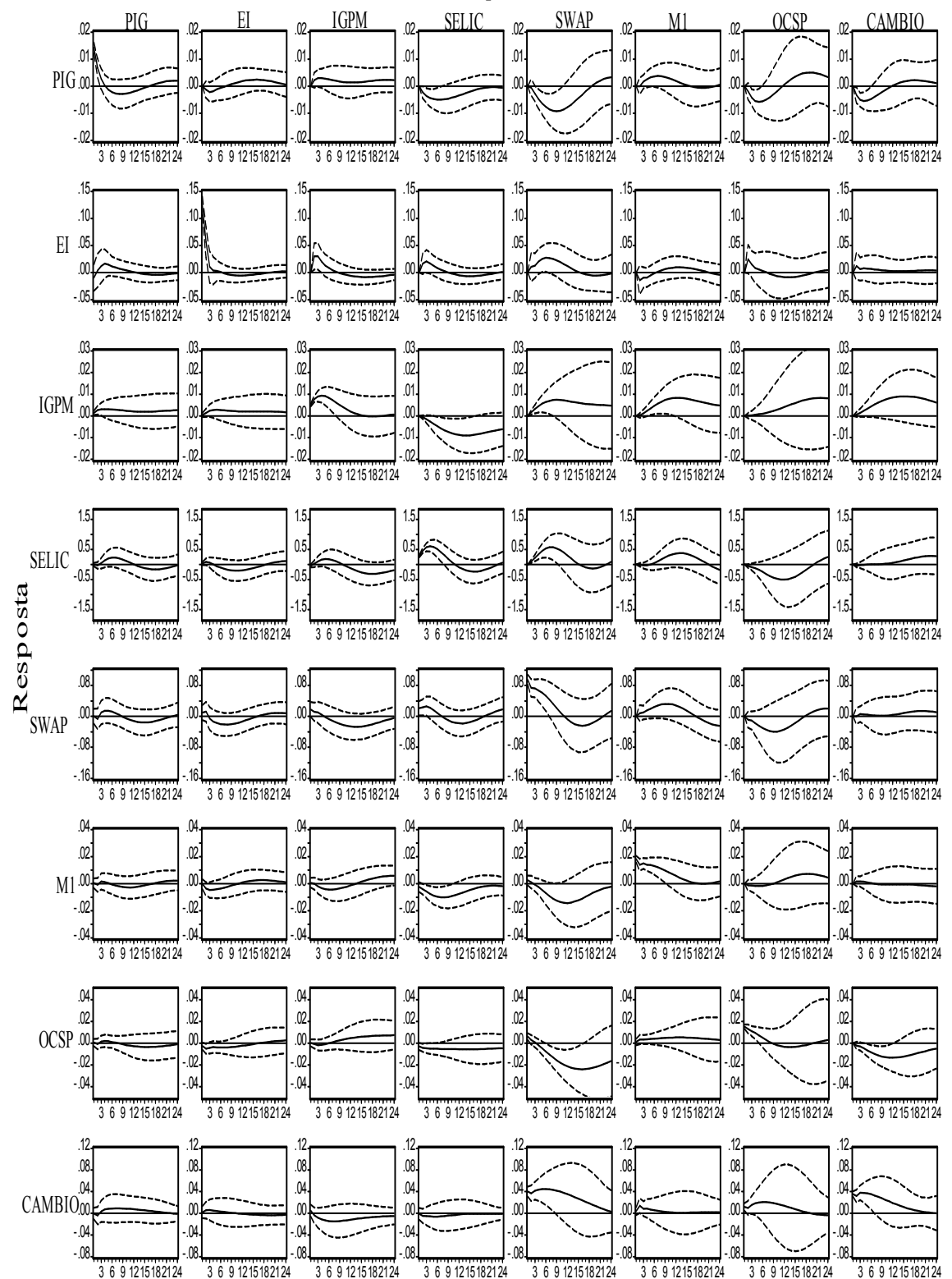

Obs.: Eixo Y: indica o nível de resposta, em percentual (à exceção da SELIC, da EI e do SWAP, em pontos percentuais) a um choque de um desvio-padrão da variável de impulso. Eixo X: defasagem do efeito, em meses. Asem meses. As linhas tracejadas indicam o intervalo de confiança de $95 \%$.

Figura 4: Funções de impulso - resposta do medelo geral com expectativas 
da SELIC neste setor é de $-1,2 \%$ (quatro meses) a -1,6\% (dez meses) para os modelos MGEA e MGP respectivamente, sendo que este foi o setor que apresentou maior discrepância entre os modelos. O efeito do SWAP é relevante, sendo maior $(-2,7 \%)$ e ocorrendo após dez meses do choque inicial. Este resultado está de acordo com a constatação do efeito do SWAP no PIG no modelo MGE, e indica que o efeito de espalhamento da sinalização da política monetária para a atividade real se dá em grande parte via redução da produção de bens de consumo duráveis. O setor de Veículos Automotivos se comporta de modo semelhante, com mesmas defasagens e níveis de efeito. O canal do financiamento para a compra parece ser o mais relevante para a conformação de efeitos identificada.

O choque máximo da SELIC à Indústria de Bens de Capital ocorre em seis meses para os três modelos, com intensidade de $-0,8 \%$ a $-1 \%$. A grande resposta deste setor a um choque exógeno do SWAP, do mesmo modo que o verificado para o setor de bens de consumo duráveis, sugere que a estrutura a termo afeta a produção pelos bens que representam ativos de mais longo prazo. Seu efeito máximo é de $-1,4 \%$, e ocorre no nono mês após o choque. A permanência do efeito verificado, que cessa em pouco menos de dois anos, pode também ocorrer devido à irreversibilidade dos projetos de investimento já em curso, e também dos contratos firmados de fornecimento dos bens de capital, o que faz com que parte do efeito seja mais defasado. O canal da taxa de juros parece ser importante para este setor. O aumento da taxa de juros de curto prazo afeta a estrutura a termo, e consequentemente altera a taxa de juros real e o requerimento de remuneração dos investimentos. O canal do preço dos ativos e o mecanismo do $q$ de Tobin também podem ser importantes para a magnitude deste efeito, que prevêem a reação negativa do investimento em decorrência da queda do preço dos ativos.

A produção da Indústria de Construção Civil reage a uma inovação monetária em, no máximo, $-0,3 \%$, entre o sexto e sétimo mês, e o efeito se torna nulo ainda em um ano. O choque do SWAP é mais longo e forte, chegando a $-1 \%$ no décimo mês, e cessando em não menos de dois anos. Novamente, verifica-se a maior relevância de choques nas taxas de juros de maior prazo na produção de ativos de maior prazo e dependentes de financiamento, verificados para os setores PIBCD, PIVA e PIBC.

Para a Indústria de Bens Intermediários, o efeito máximo do choque da Selic, de $-0,5 \%$ ocorre entre seis e nove meses e cessa em até vinte meses. A resposta à taxa de juros de longo prazo é um pouco maior $(-0,7 \%)$. A defasagem da resposta verificada pode ser justificada pelo fato de que a decisão de redução de produção não ocorre ao mesmo tempo em que os contratos de fornecimento se encerram ou são renegociados, e também pelo efeito de espalhamento da contração monetária sobre os demais setores.

O grande efeito verificado pelos setores de Bens de Consumo Duráveis e de Bens de Capital é consistente com o resultado verificado pelo modelo semi-estrutural de Minella \& Souza-Sobrinho (2009). Neste trabalho, a taxa de juros de pessoa física, diretamente vinculada ao financiamento dos bens de consumo duráveis, foi o canal responsável por mais da metade da queda do produto total ao longo do primeiro ano. O canal da taxa de juros das empresas, que possui grande impacto no setor de Bens de Capital, apresenta o segundo efeito dominante, e representou pouco menos da metade da anterior. A relevância destes setores também foi verificada no presente estudo, uma vez que apresentaram as duas maiores respostas entre os setores por tipo de uso 

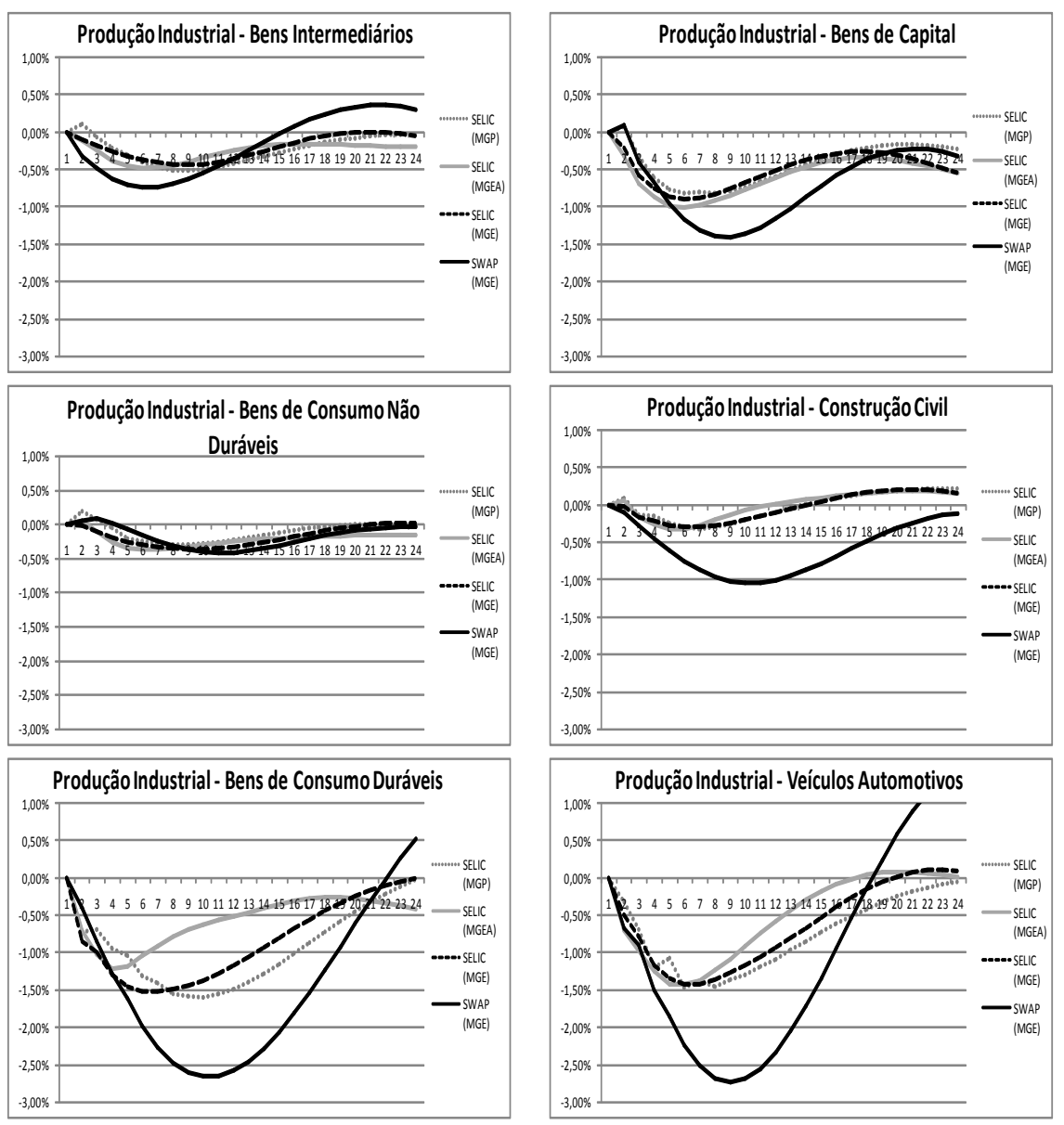

Figura 5: Funções de impulso - resposta da produção dos setores industriais e choques da SELIC e SWAP

(dentre os quais PIBC, PIBCD, PIBCND e PIBI).

Os resultados dos modelos setoriais podem ser agrupados em relação à demanda dos setores analisados:

1. Demanda de bens duráveis pelas famílias: constituído pelas indústrias de bens de consumo duráveis, de veículos e de construção civil. Os dois primeiros apresentam os maiores valores máximos de resposta à SELIC (em torno de $-1,5 \%$ ), e também a SWAP (mais de -2,5\%). A defasagem de efeitos máximos da SELIC e SWAP são um pouco maiores que os picos de respostas das próprias defasagens de resposta máxima da SELIC e SWAP à inovação monetária, o que evidencia a importância das taxas de juros de maior prazo nas decisões de produção. Pelo lado da demanda, isso pode ser explicado pela necessidade de financiamento para a compra dos bens produzidos nestas indústrias, ou seja, as famílias são sensíveis às condições de financiamento para a compra de bens de consumo duráveis e automóveis, e a produção responde com pouca defasagem à queda da demanda. O setor de construção civil apresenta respostas semelhantes, mas com nível de efeito menor; 
2. Demanda industrial: engloba as indústrias de bens intermediários e de bens de capital, que apresentam faixas de resposta máximas de $-0,5 \%$ e $-1 \%$, respectivamente. A indústria de bens de capital apresenta efeito semelhante aos de bens de consumo duráveis, por produzir ativos de prazo mais longo, e que envolvem decisões investimento, que dependem das condições gerais da economia. A resposta deste setor ao choque da SELIC é, por este motivo, mais rápido que o do setor de bens intermediários. A demanda por insumos, por outro lado, responde de modo mais lento que a de bens de capital, pois, além da demora na revisão dos contratos de fornecimento, existe um efeito de propagação da restrição na economia que atinge por último os setores de insumo, o início da cadeia produtiva;

3. Demanda de bens de consumo não duráveis: constituída pela indústria de bens de consumo não durável, que reflete o efeito renda e do canal de riqueza, após a difusão dos efeitos da política monetária pelos outros setores. A produção industrial de bens de consumo não duráveis apresentou as menores respostas, o que vai ao encontro da expectativa da suavização do consumo.

De modo geral, os setores industriais brasileiros se comportam de forma semelhante com os identificados para países desenvolvidos, como EUA, Reino Unido, França, Alemanha e Itália (Bernanke \& Gertler 1995), (Ganley \& Salmon 1997), (Dedola \& Lippi 2005): o setor de bens de consumo duráveis é um dos que sofre maior impacto, o setor de bens de consumo não-duráveis apresenta baixo impacto e os de demanda industrial (intermediários e de capital) resultados intermediários. Mesmo assim, a defasagem média de resposta máxima nestes países é maior que no Brasil, o que se supõe decorra dos motivos expostos na seção 5.1 .

\section{Considerações Finais}

Este artigo teve como objetivo investigar características importantes da política monetária e da sua transmissão na economia brasileira sob o regime de metas de inflação, de junho de 1999 a1999 a dezembro de 2008, entre elas as respostas das principais variáveis macroeconômicas aos choques de política monetária exógena e não esperada e a reação da produção industrial desagregada, com o objetivo de verificar como se comportam os setores industriais. A análise perfaz seis setores industriais, entre eles os de Bens de Consumo Duráveis, Bens de Consumo Não Duráveis, Bens de Capital, Bens Intermediários, Veículos Automotivos e Construção Civil, partindo de modelos gerais que englobam variáveis macroeconômicas relevantes para a mensuração do componente exógeno da política monetária.

Para tal fim, utilizou-se de metodologia própria para este tipo de estudo, com a estimação de modelos VAR para captar o efeito exógeno da política monetária nas principais variáveis macroeconômicas. Foram estimados três modelos distintos, de modo a garantir a robustez das relações identificadas. Primeiramente se estimou um modelo mais parcimonioso, englobando as variáveis de taxa básica de juros (definida como a variável de política monetária), produção industrial, nível de preços, agregados monetário e de crédito e taxa de câmbio. O segundo modelo incluiu ainda aspectos relevantes de uma 
economia aberta, como importações, exportações, um indicador de risco-país, taxa de juros externa e preços de commodities internacionais. O último modelo considerou variáveis de formação de expectativas, as quais a taxa de juros futura e a expectativa de inflação. Os dados foram utilizados em nível, sendo que se adotou a metodologia de Toda \& Yamamoto (1995) para contornar os problemas de não-estacionariedade das séries.

A estimação das Funções de Impulso-Resposta para os modelos testados apresentou resultados robustos entre os modelos. A produção é consistentemente afetada pelo choque exógeno de política monetária, sendo que o efeito máximo ocorre entre cinco e oito meses e o nível de produção industrial volta à sua tendência de longo prazo em menos de dois anos, o que torna o efeito da política monetária brasileira pelo menos duas vezes mais rápida no espalhamento de sua transmissão, se comparado a economias desenvolvidas, diferença que vem sendo explicada pela predominância do crédito de curto prazo na economia brasileira.

Por outro lado, o papel das taxas de juros de prazo mais longo é verificado como relevante. A taxa de juros de curto prazo afeta as de longo prazo com pouca defasagem, e as alterações na estrutura a termo geram respostas negativas na produção industrial, com uma defasagem de efeito máximo um pouco maior que o efeito da taxa de curto prazo, o que é evidência de um mecanismo de transmissão da política através da estrutura a termo. Além disso, a elevação das expectativas de taxas de juros impacta positivamente a taxa de juros de curto prazo. O que não é claro é se o Banco Central sinaliza, gera expectativas e cumpre a sinalização, ou se está apenas "seguindo o mercado", ou seja, atuando de forma a não desapontar as expectativas formadas devido a custos de reputação.

Em todos os modelos o nível de preços reage negativamente a um choque contracionista, sendo este efeito permanente. O price puzzle - uma elevação dos preços e da inflação logo após a contração monetária - é verificado com um grau muito pequeno para o modelo mais parcimonioso, e desaparece para os demais modelos, o que é uma indicação de boa modelagem do choque exógeno de política monetária. Por outro lado, identifica-se um puzzle em relação ao choque contracionista nas expectativas de inflação, o que pode ser ocasionado pela rigidez informacional na formação de expectativas, e merece investigação adicional. Além disso, o efeito pass-through da taxa de câmbio para os preços também se mostrou relevante.

As características da função de reação da autoridade monetária se mostraram, no geral, de acordo com o esperado, com exceção da resposta a choques nos níveis de preços. As variáveis de maior influência na determinação da taxa de juros são ela mesma e a taxa de câmbio. A primeira relação indica uma importante característica auto-regressiva e sugere que a política monetária vem seguindo uma ação gradualista, de modo a evitar um overshooting. A defasagem deste efeito é semelhante ao do pass-trough cambial ao nível de preços, o que significa que o Banco Central apenas reage ao choque cambial na medida em que ele é transmitido para os preços.

A Selic reage de modo consistentemente positivo à atividade industrial no modelo mais parcimonioso. No modelo de economia aberta, as exportações passam a ser o principal fonte de impacto real na definição da taxa básica de juros e no de expectativas a taxa de juros de longo prazo se mostra mais relevante.

Os efeitos e defasagem apresentam resultados diversos para os agrupa- 
mentos de indústrias considerados. Os de demanda industrial (Bens Intermediários e de Capital) apresentaram características de prolongamento do efeito das decisões de investimento e demora nas revisões e conclusões de contratos de fornecimento, que resultaram em grande efeito máximo, principalmente na demanda de bens que constituem ativos de longo prazo, o caso do setor de Bens de Capital.

Os de demanda de bens duráveis pelas famílias (Bens de Consumo Duráveis, Veículos Automotivos e Construção Civil) apresentam resposta ainda maior e com defasagem de efeito máximo entre quatro e dez meses, além de respostas maiores e com maior defasagem em relação à taxa de juros de longo prazo. O choque para estes setores é visivelmente mais rápido e forte, o que reflete que a decisão de redução da demanda destes bens está ligada ao mercado de crédito para consumo, uma vez que o efeito na taxa de juros é imediato.

O terceiro grupo, composto pela Indústria de Bens de Consumo Não Duráveis, apresenta resultado diverso: as famílias suavizam o consumo e, portanto, o efeito é o mais baixo, sendo não significativo, uma vez que o efeito predominante é o da redução da renda. Este resultado está de acordo com a teoria do ciclo de vida de Modigliani e com a suposição de suavização do consumo.

Para futuros estudos nessa área, indica-se o desmembramento dos setores industriais na análise e a incorporação dos setores de serviço e de agricultura, outros componentes do lado da demanda. Outro caminho a seguir é o cruzamento de informações sobre a capacidade de autofinanciamento, de acesso a fontes alternativas e do próprio mercado de crédito que captem melhor as particularidades de cada setor, de modo a inferir sobre a relevância do canal do crédito na economia brasileira.

\section{Referências Bibliográficas}

Alam, T. \& Waheed, M. (2006), The monetary transmission mechanism in pakistan: a sectoral analysis, Technical report, University Library of Munich.

Arnold, I. J. M. \& Vrugt, E. B. (2002), 'Regional effects of monetary policy in the netherlands', International Journal of Business and Economics 1, 123-134.

Arquete, L. \& Jayme-Jr., F. (2003), Política monetária, preços e produto no brasil (1994-2002): Uma aplicação de vetores auto-regressivos., in 'XXXI Encontro Nacional de Economia da ANPEC'.

Barbosa, F. H. (2006), 'The contagion effect of public debt on monetary policy: the brazilian experience.', Revista de Economia Política 26, 231-238.

Bernanke, B. \& Blinder, A. (1992), 'The federal funds rate and the channels of monetary transmission.', American Economic Review 82, 901-921.

Bernanke, B. \& Gertler, M. (1995), 'Inside the black box: the credit channel of monetary policy transmission.', Journal of Economics Perspectives 9, 27-48.

Bernanke, B. \& Mihov, I. (1998), 'Measuring monetary policy.', Quartely Journal of Economics 103, 869-902.

Caballero, R. \& Krishnamurthy, A. (2004), A. fiscal policy and financial depth., Technical report, NBER. 
Carneiro, D. D., Salles, F. M. \& Wu, T. Y. H. (2006), 'Juros, câmbio e as imperfeições do canal do crédito.', Economia Aplicada 10, 7-23.

Christiano, L. J., Eichenbaum, M. \& Evans, C. (1999), Monetary policy shocks: what have we learned and to what end?, in 'Handbook of Macroeconomics', Elsevier Science/North Holland.

Correa, A. S. \& Minella, A. (2005), Mecanismos não-lineares de repasse cambial: Um modelo de curva de phillips com threshold para o brasil., in 'XXXIII Encontro Nacional de Economia da ANPEC'.

Cushman, D. O. \& Zha, T. (1997), 'Identifying monetary policy in a small open economy under flexible exchange rates.', Journal of Monetary Economics 39, 433-448.

Céspedes, B., Lima, E. \& Maka, A. (2008), 'Monetary policy, inflation and the level of economic activity in brazil after the real plan: stylized facts from svar models.', Revista Brasileira de Economia 62, 123-160.

Dedola, L. \& Lippi, F. (2005), 'The monetary transmission mechanism: evidence from the industries of five oecd countries.', European Economic Review 49, 1543-1569.

Enders, W. (2004), Applied econometric time series, Hoboken.

Favero, C. \& Giavazzi, F. (1999), An evaluation of monetary policy transmission in the context of the european central bank., Technical report, Report to the European Parliament.

Fernandes, M. \& Toro, J. (2005), 'O mecanismo de transmissão monetária na economia brasileira pós-plano real.', Revista Brasileira de Economia 59, 5-32.

Freixas, X. \& Rochet, J. (1999), Microeconomics of banking., MIT Press.

Friedman, M. \& Schwartz, A. J. (1963), Monetary History of the United States - 1867-1960., Princeton University Press.

Ganley, J. \& Salmon, C. (1997), The industrial impact of monetary policy shocks: Some stylized facts., Technical report, Bank of England.

Gertler, M. \& Gilchrist, S. (1993), 'The role of credit market imperfections in monetary transmission mechanism: arguments and evidence.', Scandinavian Journal of Economics 95, 43-64.

Giambiagi, F. (2002), 'Do déficit de metas às metas de déficit: a política fiscal do governo fernando henrique cardoso - 1995/2002.', Pesquisa e Planejamento Econômico 32, 1-48.

Giambiagi, F. (2006), A política fiscal do governo lula em perspectiva histórica: qual é o limite para o aumento do gasto público?, Technical report, IPEA.

Goldfajn, I. \& Werlang, S. (2000), The pass-through from depreciation to inflation: A panel study., Technical report, Banco Central do Brasil. 
Graminho, F. M. \& Bonomo, M. A. (2002), O canal de empréstimos bancários no brasil: Uma evidência microeconômica., in 'XXX Encontro Nacional de Economia da ANPEC'.

Guillèn, D. A. (2008), Ensaios sobre a formação de expectativas de inflação., Master's thesis, Pontifícia Universidade Católica do Rio de Janeiro.

Ibrahim, M. H. (2005), 'Sectoral effects of monetary policy: evidence from malaysia.', Asian Economic Journal 19, 83-102.

Lima, A. M. \& Issler, J. V. (2003), 'A hipótese das expectativas na estrutura a termo de juros no brasil: uma aplicação de modelos de valor presente.', Revista Brasileira de Economia 57, 873-898.

Lima, D. A. R. \& Jorge-Neto, P. M. (2004), Política monetária e preço dos ativos: Um estudo do mecanismo de transmissão no brasil., in 'IX Encontro Regional de Economia ANPEC/NE'.

Lopes, F. (1997), 'O mecanismo de transmissão da política monetária numa economia em processo de estabilização: notas sobre o brasil.', Revista de Economia Política 17, 4-11.

Lucas, R. (1976), 'Econometric policy evaluation: a critique.', CarnegieRochester Conference Series on Public Policy. 1, 19-46.

Marçal, E. F. \& Pereira, P. L. V. (2007), 'A estrutura a termo das taxas de juros no brasil: Testando a hipótese de expectativas.', Pesquisa e Planejamento Econômico 37, 113-147.

Minella, A. (2003), 'Monetary policy and inflation in brazil (1975-2000): a var estimation.', Revista Brasileira de Economia 57, 605-635.

Minella, A. \& Souza-Sobrinho, N. F. (2009), Monetary channels in brazil through the lens of a semi-structural model., Technical report, Banco Central do Brasil.

Mishkin, F. S. (1996), The channels of monetary transmission: lessons for monetary policy., Technical report, Banque de France Bulletin Digest.

Oreiro, J. L., Paula, L. F., Ono, F. H. \& Silva, G. J. C. (2006), 'Determinantes macroeconômicos do spread bancário no brasil: teoria e evidência recente.', Economia Aplicada 10, 609-634.

Pires, M. C. C. \& Andrade, J. P. (2008), Um arcabouço para análise da transmissão da política monetária e o canal da dívida pública no brasil, in 'XXXVI Encontro Nacional de Economia da ANPEC'.

Romer, D. \& Romer, C. (1989), Does monetary policy matter? a new test in the spirit of friedman and schwartz., in 'Macroeconomics Annual', MIT Press.

Schwartzman, F. F. (2006), 'Estimativa de curva de phillips para o brasil com preços desagregados.', Economia Aplicada 10, 137-155.

Silva-Filho, O. C., Silva, L. C. \& Frascaroli, B. F. (2006), Política monetária e mudanças macroeconômicas no brasil: uma abordagem ms-var, Technical report, Fórum do Banco do Nordeste. 
Sims, C. (1992), 'Interpreting the macroeconomic time series facts: the effects of monetary policy.', European Economic Review 36, 975-1000.

Sims, C. A., Stock, J. H. \& Watson, M. W. (1990), 'Inference in linear time series models with some unit roots.', Econometrica 58, 113-144.

Takeda, T., Rocha, F. \& Nakane, M. (2005), 'The reaction of bank lending to monetary policy in brazil.', Revista Brasileira de Economia 59, 107-126.

Taylor, J. B. (1995), 'The monetary transmission mechanism: an empirical framework.', Journal of Economic Perspectives 9, 11-26.

Tejada, C. A. O. \& Silva, A. G. (2008), 'O pass-through das variações da taxa de câmbio para os preços dos principais produtos exportados pelo brasil.', Revista de Economia e Sociologia Rural 46, 171-205.

Toda, H. Y. \& Yamamoto, T. (1995), 'Statistical inference in vector autoregressions with possibly integrated processes.', Journal of Econometrics 66, 225250. 